\title{
Carcinoma de células de Merkel tratado con radioterapia como monoterapia: informe de caso y revisión de las publicaciones médicas
}

\section{Merkel cell carcinoma treated with radiotherapy as monotherapy: case report and literature review}

\author{
Arturo Robles-Tenorio, Leslie E. Rocha-Méndez y Víctor M. Tarango-Martínez* \\ Instituto Dermatológico de Jalisco “Dr. José Barba Rubio", Zapopan, Jalisco, México
}

\section{Resumen}

El carcinoma de células de Merkel (CCM) es una neoplasia cutánea de origen neuroendocrino, de rápida evolución y muy agresiva. Se presenta el caso de una paciente con diagnóstico de CCM (T2NOMO, estadio IIA) en el labio superior, quien rechazó el tratamiento quirúrgico y reconstructivo. En consecuencia, se ofreció y administró radioterapia como monoterapia. A los 60 meses de seguimiento, la paciente continuó sin recidivas. Este texto expone la evidencia de la radioterapia como monoterapia en el CCM.

Palabras clave: Carcinoma neuroendocrino de piel. Tumor neuroendocrino maligno. Radiación.

\begin{abstract}
Merkel Cell Carcinoma (MCC) is a rapidly growing, neuroendocrine, cutaneous malignancy with a high metastatic potential. Here, we present a case of MCC (T2NOMO stage IIA) affecting the upper lip. The patient rejected surgical treatment, thus radiotherapy as monotherapy was administered. At the 60-month follow-up, the patient showed no signs of recurrence. This case report reviews the evidence of radiotherapy as monotherapy in MCC.
\end{abstract}

Key words: Carcinoma. Merkel cell. Skin neoplasms. Radiotherapy. Adjuvant.

\section{Introducción}

El carcinoma de células de Merkel (CCM) es un tumor neuroendocrino cutáneo, infrecuente, de crecimiento rápido, potencialmente letal y con gran capacidad metastásica ${ }^{1}$. El tratamiento de elección comprende la escisión del tumor con márgenes amplios. La radioterapia como monoterapia puede utilizarse en la enfermedad limitada a piel o locorregional, en particular cuando hay factores de alto riesgo para la cirugía o el paciente rechaza el procedimiento. En este informe se presenta un caso de CCM confinado a la piel, que se trató sólo con radioterapia.

\section{Caso clínico}

Mujer previamente sana de 61 años que acude por un tumor asintomático de dos meses de evolución localizado en el labio superior. En la exploración
Correspondencia:

*Víctor M. Tarango-Martínez E-mail: drtarangovic@gmail.com
Fecha de recepción: 09-12-2020 Fecha de aceptación: 15-03-2021 DOI: 10.24875/MCUT.20000170
Disponible en internet: 06-10-2021 Med Cutan Iber Lat Am. 2021;49(Suppl 1):51-53 www.MedicinaCutanealLA.com 0210-5187/C 2021 Colegio Ibero Latinoamericano de Dermatología A.C. (CILAD). Publicado por Permanyer. Este es un artículo open access bajo la licencia CC BY-NC-ND (http://creativecommons.org/licenses/by-nc-nd/4.0/) 
física se identificó una neoformación de 1.7 x 1.4 x $0.6 \mathrm{~cm}$, de color rosado, con telangiectasias en su superficie, bordes precisos y consistencia firme (Fig. 1). No se encontraron linfadenopatías, organomegalias ni otras lesiones cutáneas. El estudio histopatológico reveló un tumor de células pequeñas redondas y azules con patrón trabecular. La inmunohistoquímica fue positiva para enolasa neuronal específica (ENE) y citoqueratina 20 (CK20) (Fig. 2). La tomografía axial computarizada descartó invasión en ganglios adyacentes. Se estableció el diagnóstico de carcinoma de células de Merkel (CCM) (T1NOMO, estadio I) y se programó para escisión con márgenes amplios. En el día del procedimiento, el tumor había duplicado su tamaño (T2NOMO, estadio IIA). Al revisarse las nuevas opciones de reconstrucción, la paciente rechazó el procedimiento. Se indicó tratamiento con radioterapia como monoterapia hasta alcanzar una dosis acumulativa de 60 Gy en 25 sesiones (cuatro por semana). La vigilancia se realizó cada tres meses. A los 60 meses de seguimiento la paciente continuó sin recidiva tumoral.

\section{Discusión}

EI CCM tiene una incidencia creciente, estimada entre de 0.3 a 1.6 personas por año, y afectando sobre todo a pacientes de 70 a 80 años $^{1}$. De acuerdo con la guía estadounidense de práctica clínica y el consenso europeo ${ }^{2,3}$, el tratamiento de elección es la escisión con márgenes amplios $(1-2 \mathrm{~cm})$, con o sin radioterapia adyuvante. La guía estadounidense recomienda la biopsia de ganglio centinela en casos que carezcan de linfadenopatía clínica, para pautar el uso de radioterapia en los sitios de drenaje linfático. La radioterapia como monoterapia puede realizarse en casos inoperables o cuando el paciente rechace la operación. La dosis recomendada es de 50 a 66 Gy, fraccionada a 2 Gy/día con inclusión de $5 \mathrm{~cm}$ como margen de seguridad. El seguimiento debe comprender exploración física de piel y ganglios linfáticos cada tres a seis meses durante los primeros tres años y luego cada seis a 12 meses de por vida. Los estudios de imagen están indicados cuando existan adenomegalias, organomegalias, síntomas sistémicos, inmunosupresión y en fases mayores de IIIB².

El CCM ha mostrado ser una neoplasia muy radiosensible en diversos estudios. La radioterapia como monoterapia puede alcanzar un adecuado control en el campo de irradiación en $75 \%$ a $88 \%$ de los $\operatorname{casos}^{4-6}$. En un estudio comparativo no se observó diferencia estadísticamente significativa en la supervivencia global ni en la

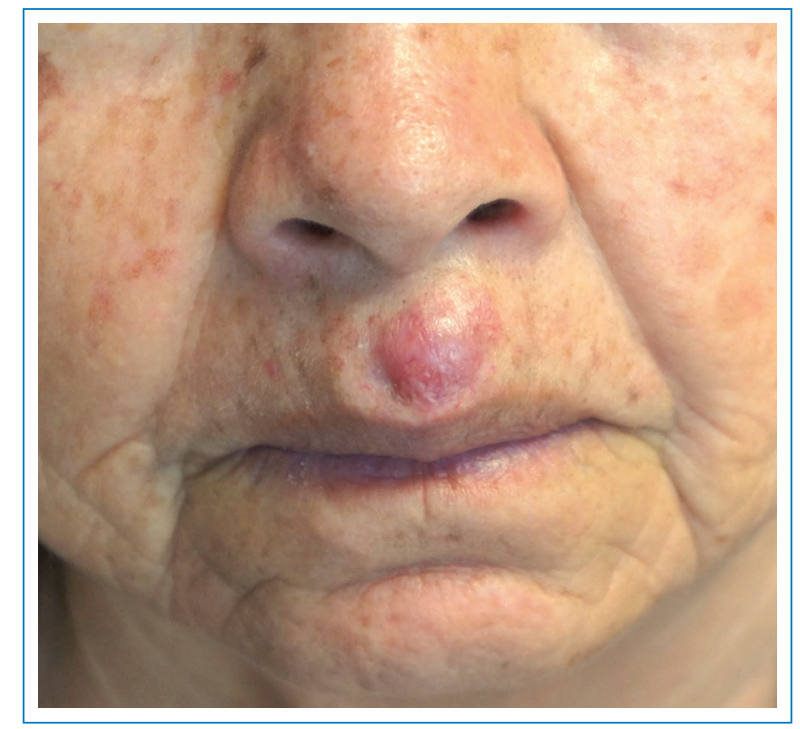

Figura 1. Aspecto clínico. Neoformación localizada en labio superior.

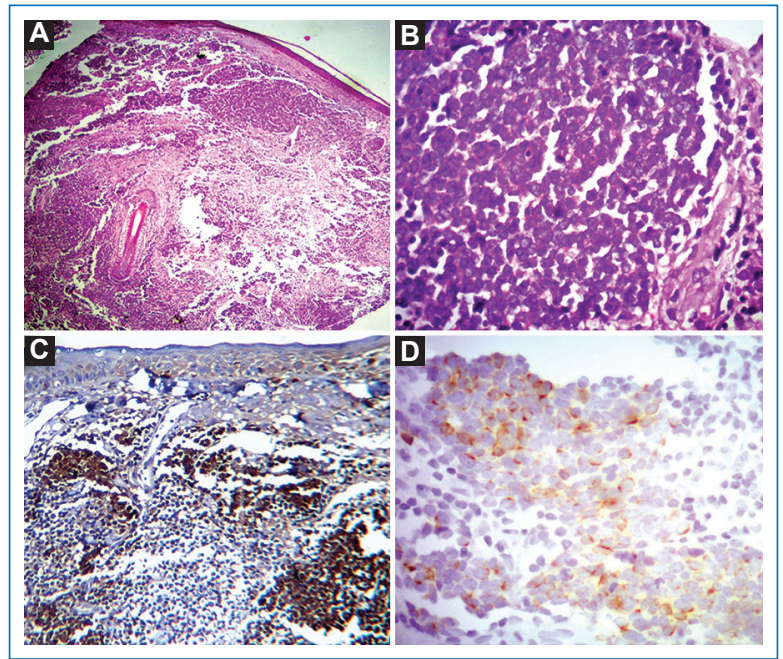

Figura 2. Estudio histopatológico. A: el tumor infiltra la totalidad de la dermis. B: la malformación se compone de células pequeñas, redondas y azules, de citoplasma escaso que forman cordones. C: inmunohistoquímica positiva para enolasa neuronal específica. D: citoqueratina 20 en patrón paranuclear.

supervivencia libre de enfermedad entre el grupo tratado con radioterapia como monoterapia $(n=9)$ y la cirugía de márgenes ampliados más radioterapia adyuvante (n $=17)^{7}$. De manera notable, sólo el segundo grupo tuvo una recurrencia y una progresión a metástasis. 
Otro estudio similar señaló que las recidivas locorregionales se observaron en el $4 \%$ de los pacientes tratados sólo con radioterapia $(n=25)$, en comparación con un $16 \%$ de los sometidos a abordaje quirúrgico y radioterapia $(\mathrm{n}=25)^{8}$.

En otra cohorte, la supervivencia sin recidiva regional a dos años fue mayor en pacientes con linfadenopatía palpable que recibieron sólo irradiación de ganglios linfáticos $(78 \%)$ en contraste con la linfadenectomía, con o sin radioterapia adyuvante $(73 \%)^{9}$. Además, los individuos tratados con radioterapia como monoterapia mostraron una supervivencia específica de la enfermedad a dos años del $83 \%$ y $73 \%$, de acuerdo con la afectación microscópica o clínica de los ganglios linfáticos, respectivamente.

En un caso de CCM (T3N1bMO estadio IIIB) en el labio superior se documentó la radioterapia del sitio primario y el cuello, junto con escisión del ganglio submentionano afectado, debido a que el paciente rechazó el tratamiento quirúrgico de la neoplasia ${ }^{10}$. Tres meses después del tratamiento se identificó una remisión completa del tumor, sin mostrar recidivas al año de seguimiento. En la misma publicación, los autores analizaron 22 casos de CCM (estadios I-IV) tratados con radioterapia como monoterapia en Japón y registraron un $95.5 \%$ de respuesta completa al tratamiento.

En conclusión, este caso describe una patología que exige la integración oportuna de un equipo multidisciplinario entre los servicios de cirugía dermatológic y radiooncología. En esta paciente, el seguimiento dermatológico y radiooncológico a 60 meses apoya el uso de la radioterapia como monoterapia en tumores confinados a la piel, sobre todo cuando las técnicas de reconstrucción sean de alto riesgo o no las acepte el paciente.

\section{Financiamiento}

Los autores declaran no haber recibido financiamiento para la realización de este trabajo.

\section{Conflicto de intereses}

Los autores declaran no tener ningún conflicto de intereses.

\section{Responsabilidades éticas}

Protección de personas y animales. Los autores declaran que para esta investigación no se han realizado experimentos en seres humanos ni en animales.

Confidencialidad de los datos. Los autores declaran que en este artículo no aparecen datos de pacientes.

Derecho a la privacidad y consentimiento informado. Los autores han obtenido el consentimiento informado de los pacientes y/o sujetos referidos en el artículo. Este documento obra en poder del autor de correspondencia.

\section{Bibliografía}

1. Becker JC, Stang A, DeCaprio JA. Merkel cell carcinoma. Nat Rev Dis Prim. 2017;3(1):1-17

2. Bichakjian CK, Olencki T, Aasi SZ. Merkel cell carcinoma, version 1.2018, NCCN clinical practice guidelines in oncology. J Natl Compr Cancer Netw. 2018;16(6):742-774

3. Lebbe C, Becker JC, Grob JJ. Diagnosis and treatment of Merkel cell carcinoma. European consensus-based interdisciplinary guideline. Eur J Cancer. 2015;51(16):2396-2403.

4. Veness M, Foote M, Gebski V, Poulsen M. The role of radiotherapy alone in patients with Merkel cell carcinoma: reporting the Australian experience of 43 patients. Int $\mathrm{J}$ Radiat Oncol Biol Phys. 2010;78(3):703-709

5. Veness M, Howle J. Radiotherapy alone in patients with $M$ erkel cell carcinoma: The W estmead Hospital experience of 41 patients. Australas J Dermatol. 2015;56(1):19-24.

6. Harrington C, Kwan W. Outcomes of Merkel cell carcinoma treated with radiotherapy without radical surgical excision. Ann Surg Oncol. 2014:21(11):3401-3405.

7. Mortier L, Mirabel X, Fournier C, Piette F, Lartigau E. Radiotherapy alone for primary Merkel cell carcinoma. Arch Dermatol. 2003;139(12):1587-1590.

8. Pape E, Rezvoy N, Penel N. Radiotherapy alone for Merkel cell carcinoma: a comparative and retrospective study of 25 patients. J Am Acad Dermatol. 2011;65(5):983-990.

9. Fang LC, Lemos B, Douglas J, lyer J, Nghiem P. Radiation monotherapy as regional treatment for lymph node-positive Merkel cell carcinoma. Cancer Interdiscip Int J Am Cancer Soc. 2010;116(7):1783-1790.

10. Kitamura N, Tomita R, Yamamoto M. Complete remission of Merkel cell carcinoma on the upper lip treated with radiation monotherapy and a literature review of Japanese cases. World J Surg Oncol. 2015;13:152. 